\title{
Network Reliability Analysis as a Tool to Guide Investment Decisions in Distributed Generation
}

\author{
Samson Ttondo Ssemakalu1, Milton Edimu' ${ }^{1}$, Jonathan Serugunda', Patrick Kabanda ${ }^{2 *}$ \\ ${ }^{1}$ Department of Electrical and Computer Engineering, Makerere University, Kampala, Uganda \\ ${ }^{2}$ School of Engineering and Applied Sciences, Kampala International University, Kampala, Uganda \\ Email:samson.ssemakalu@umeme.co.ug,miltonedimu@yahoo.com,serugthan@gmail.com, „pkabanda1@gmail.com
}

How to cite this paper: Ssemakalu, S.T., Edimu, M., Serugunda, J. and Kabanda, P. (2018) Network Reliability Analysis as a Tool to Guide Investment Decisions in Distributed Generation. Journal of Power and Energy Engineering, 6, 64-84. https://doi.org/10.4236/jpee.2018.69008

Received: August 12, 2018

Accepted: September 26, 2018

Published: September 29, 2018

Copyright $\odot 2018$ by authors and Scientific Research Publishing Inc. This work is licensed under the Creative Commons Attribution International License (CC BY 4.0).

http://creativecommons.org/licenses/by/4.0/

\begin{abstract}
Distributed Generation (DG) in any quantity is relevant to supplement the available energy capacity based on various locations, that is, whether a site specific or non-site specific energy technology. The evacuation infrastructure that delivers power to the distribution grid is designed with appropriate capacity in terms of size and length. The evacuation lines and distribution network however behave differently as they possess inherent characteristics and are exposed to varying external conditions. It is thus feasible to expect that these networks behave stochastically due to fault conditions and variable loads that destabilize the system. This in essence impacts on the availability of the evacuation infrastructure and consequently on the amount of energy delivered to the grid from the DG stations. Reliability of the evacuation point of a DG is however not a common or prioritized criteria in the decision process that guides investment in DG. This paper reviews a planned solar based DG plant in Uganda. Over the last couple of years, Uganda has seen a significant increase in the penetration levels of DG. With a network that is predominantly radial and experiences low reliability levels, one would thus expect reliability analysis to feature significantly in the assessment of the proposed DG plants. This is however not the case. This paper, uses reliability analysis to assess the impact of different evacuation options of the proposed DG plant on its dispatch levels. The evacuation options were selected based on infrastructure options in other locations with similar solar irradiances as the planned DG location. Outage data were collected and analyzed using the chi square method. It was found to be variable and fitting to different Probability Distribution Functions (PDF). Using stochastic methods, a model that incorporates the PDFs was developed to compute the reliability indices. These were assessed using chi square and found to be variable and fitting different PDFs as well. The viability of the project is reviewed based on Energy Not Supplied
\end{abstract}


(ENS) and the anticipated project payback periods for any considered evacuation line. The results of the study are also reviewed for the benefit of other stakeholders like the customers, the utility and the regulatory body.

\section{Keywords}

Deterministic Methods, Distributed Generation, Network Reliability, Reliability Analysis, Stochastic Methods

\section{Introduction}

Distributed generation (DG) is the production of power at or very close to the customer consumption point for customers tied to the electric distribution system [1]. The generation may be from both a renewable and non-renewable energy source. There is an increasing consideration for clean renewable energy sources. DG plants are small-scale energy resources that typically range in size from 0.5 MW to 20 MW as defined in the Uganda Electricity Act 1999 [2]. The advantage with DG is that the cost of transmitting the generated power to the load locations is minimized. This eventually lowers the total unit cost of energy. It is a growing venture in Uganda today with such a high energy resource potential. This includes an estimated $175 \mathrm{MW}$ of hydro power, $112 \mathrm{MW}$ of thermal, and $595 \mathrm{MW}$ of solar with an average of $5.1 \mathrm{kWh} / \mathrm{m}^{2}$ of solar energy. In addition, petroleum in an estimated amount of 6.5 billion barrels, of which 1.4 billion barrels are recoverable, has been discovered in the western part of the country. The overall renewable energy power generation potential is estimated to be 5300 MW [3]. The Uganda National Development Priorities (UNDP) is stated in Vision 2040 statement "A transformed Ugandan society from a peasant to a modern and prosperous country within 30 years". Uganda will require an estimated $4.17 \mathrm{GW}$ by 2040 thus increasing its electricity per capita consumption to 3668 $\mathrm{kWh}$, of which $3 \mathrm{GW}$ will be from renewable sources and $2.81 \mathrm{GW}$ will be connected to the national grid [4]. The Global Energy Transfer Feed In Tariff (GETFIT) Uganda project alone has identified twenty (20) Renewable Energy Feed In Tariff (REFIT) projects ranging from 1 to $20 \mathrm{MW}$, representing an estimated $170 \mathrm{MW}$ and $830 \mathrm{GWh} /$ year, to be undertaken [5]. Table 1 shows the energy capacities for the various technologies and their generation capabilities as at end of 2016 and the expected additional capacities by 2040 specifying DG contribution.

The decision to invest in DG evacuation is currently determined by the type of eligible technology, size of the project, the cap on the eligible installed capacity, geographical location, resource quality, the length of the contract with the generator and pricing of energy unit to be dispatched [6]. The technical studies usually done are focused on the impact of the DG on the grid in terms of voltages, losses, power evacuated and fault levels [7] [8]. However, little emphasis is put on the impact of the reliability of the associated grid on the amount of 
Table 1. Generation technologies in Uganda.

\begin{tabular}{ccccc}
\hline $\begin{array}{c}\text { Generation } \\
\text { Technology }\end{array}$ & $\begin{array}{c}\text { Generation } \\
\text { dispatch } \\
\text { percentage } \\
(2016)\end{array}$ & $\begin{array}{c}\text { Installed } \\
\text { Capacity } \\
(\mathrm{MW})\end{array}$ & $\begin{array}{c}\text { Evacuation } \\
\text { Generation } \\
(2016)(\mathrm{MW})\end{array}$ & $\begin{array}{c}\text { Generation } \\
\text { dispatch } \\
\text { percentage } \\
(2040)\end{array}$ \\
\hline Small Hydro & $5.9 \%$ & 50 & 33.8 & $10.9 \%$ \\
Thermal & $7.0 \%$ & 172 & 40.1 & $7 \%$ \\
Solar & $0.5 \%$ & 10 & 2.9 & $37.2 \%$ \\
\hline
\end{tabular}

dispatched energy. It is assumed, in the payment terms, that all the energy available at the plant will be dispatched. This is unrealistic given the fact that reliability of either the evacuation line or the grid point of evacuation will impact on the amount of energy dispatched. Previous contracts with DG developers include a "deemed" energy clause. This provides for compensation to the developer for energy that would have been dispatched if the evacuation grid was available. One could argue that for the deemed energy clause to be valid, the developer must demonstrate that the proposed evacuation option is the most reliable and that effort was made by the developer to maximize the dispatch from the plant. DG location and the associated evacuation have to benefit the customers supplied by the targeted distribution network. Assessment of the improvement in reliability due to integration of a DG should also be considered. This however is never the case. There is therefore a need to carry out reliability studies for the grid networks to which power is to be evacuated from the various DGs to guide decisions on DG investment. Failure to do proper reliability studies implies that most investments in DG could result in evacuation of power onto the distribution networks that have a very high probability of failure. As such the anticipated energy is not fully delivered for most of the period anticipated. This implies that the system operator will unnecessarily pay charges for deemed energy and the customers will not benefit from the given DG integration.

This paper demonstrates the need to include reliability impact assessment of the evacuation network as key criteria in assessing proposal of DGs and in the achievement of the energy deliveries as declared in the various power purchase agreements (PPAs).

\section{Methodology}

The research focused on a proposed 15 MW solar station in Eastern Uganda.

\subsection{Selection of Alternative Evacuation Lines}

The solar power project studied is proposed in the Mayuge area with solar irradiances ranging between $2200 \mathrm{kWh} / \mathrm{m}^{2}$ and $2400 \mathrm{kWh} / \mathrm{m}^{2}$. However, there are a number of other areas with similar irradiance levels [9]. The study analyses reliability of the alternative evacuation lines in areas with similar irradiances that could be considered. It also analyzed an underground cable infrastructure to as- 
sess the reliability on using a full cable run between the generation and distribution substations or connecting the underground cable to the overhead infrastructure. A line was selected for consideration if there is land where panels can be put along or very close to its path from the substation. As such, the lines in Table 2 were selected.

The proposed plant will be evacuated using the Jinja Industrial-Iganga $33 \mathrm{kV}$ line to the distribution grid. The research considers alternative locations with considerably similar solar irradiations. It assessed the reliability of distribution lines that could have been used to evacuate the plant at each of these potential locations. The outage duration and frequency data used for the reliability analysis of the distribution MV lines were taken from the UMEME SCADA system records considering a time period from 2012 to 2016. Reliability data for power distribution networks is valid if is recorded for a minimum of 5 years [10].

\subsection{Selection of Evacuation Points Using Deterministic Analysis}

The collected data was analyzed and used to select the best evacuation points. Using the deterministic analysis of the outage durations and frequencies, the averages of the historical values were determined and used as a basis for determining the most reliable line to be used for the evacuation of the generated power. The line with the lowest average duration-frequency product (unavailability) is considered to be the most appropriate line for the evacuation. The duration $r$, frequency $\lambda$ and unavailability $U$ are shown in Table 3 as the basis for the choice of line.

\subsection{Assessing Variability in the Outage Data}

The data collected was subjected to chi-square tests to assess variability and determine the best PDF for each data set. On analyzing the various data sets, it was noticed that the data follows different statistical properties and therefore should not be assessed using mere averages as is the case with the deterministic approach. It implies that there is need to analyze each data set differently based on its statistical properties as determined by the Chi-square tests for goodness of fit.

Table 2. Selected evacuation lines.

\begin{tabular}{ccccc}
\hline Substation & Feeder & Voltage $(\mathbf{k V})$ & $\begin{array}{c}\text { Length } \\
(\mathbf{k m})\end{array}$ & $\begin{array}{c}\text { Conductor } \\
\text { size }\left(\mathbf{m m}^{2}\right)\end{array}$ \\
\hline Tororo - Main & Busia & 33 & 98 & 100 \\
Bulangila & Pallisa & 11 & 110 & 25 \\
Lira & Gulu & 33 & 209 & 100 \\
Lira & Masindi & 33 & 283 & 150 \\
Hoima & Wabigalo & 33 & 107 & 100 \\
Bombo & & 33 & 115 & 150 \\
\hline
\end{tabular}


Table 3. Deterministic analysis results.

\begin{tabular}{cccc}
\hline & DURATION, $r$ & FREQUENCY, $\lambda$ & $\mathrm{U}$ \\
\hline CABLE NETWORK & 5.8 & 2.7 & 15.61 \\
OVERHEAD NETWORK & & & \\
BULANGIRA - PALLISA & 25.7 & 5.4 & 138.63 \\
HOIMA - MASINDI & 18.3 & 9.0 & 164.42 \\
BOMBO - WABIGALO & 27.5 & 7.8 & 213.20 \\
JINJA IND - IGANGA & 20.5 & 16.5 & 338.90 \\
LIRA - GULU & 75.9 & 17.2 & 1306.90 \\
TORORO MAIN - BUSIA & 59.5 & 26.1 & 1550.76 \\
LIRA - MASINDI/APAAC & 123.5 & 35.6 & 4392.71 \\
\hline
\end{tabular}

\subsubsection{Goodness-of-Fit Tests for the Outage Data}

The outage duration and frequency data collected was tested using the Chi-Square test for goodness-of-fit to determine the suitable PDF to use for each. It was noticed that different data sets fit different PDFs. The percentage deviation between the statistical and the table Chi-Square values is obtained using equation 1 and shown in Table 4 and Table 5 with a dark shade.

$$
\text { percentage deviation }=\frac{\text { statistical value }- \text { table value }}{\text { statistical value }} \times 100
$$

\subsubsection{Data Fitting to the Distributions}

The study considered the four (4) major PDFs, i.e. Normal, Exponential, Weibull and Beta. The properties of the various distributions considered for the analysis were determined and used to analyze the data. To analyze the data the following steps were taken.

1) Divide the data set into a number of subintervals

2) Standardize the end point of each subinterval.

3) Compute the cumulative probability for each subinterval. This can be done using the inbuilt excel function.

4) Compute the cell probability for each subinterval. This is got by determining the difference between the computed cumulative probabilities for the subintervals.

5) Determine the expected values for the subintervals. This is done by multiplying the cell probabilities by the total number of elements in the data set.

6) The chi square value can then be calculated using Equation (2).

$$
X_{c}^{2}=\sum \frac{\left(O_{i}-E_{i}\right)^{2}}{E_{i}}
$$

Where $O$ is the observed value, $E$ is the expected value, the subscripts " $c$ " and " $i$ " represent the degrees of freedom and the $i$ th position in the table, respectively.

7) Compare the calculated value in step (6) with the table value from the standard chi square tables. This requires computation of the Degree of Freedom (D.F).

$$
\text { D.F }=\text { No. of subintervals }- \text { No. of parameters }-1
$$


Table 4. Most fitting PDF for the duration data sets.

\begin{tabular}{lccccc}
\hline DISTRIBUTION $\begin{array}{c}\text { JINJA } \\
\text { IND-IGANG MAIN-BUSIA }\end{array}$ & $\begin{array}{c}\text { TORR } \\
\text { BULG-PALLIS LIRA-GULU }\end{array}$ & $\begin{array}{c}\text { LIRA-MASD/ } \\
\text { APAAC }\end{array}$ & $\begin{array}{c}\text { HOIMA- } \\
\text { MASINDI }\end{array}$ & $\begin{array}{c}\text { BOMBO- } \\
\text { WABIGAL }\end{array}$ & $\begin{array}{c}\text { PIONEER } \\
\text { MALL }\end{array}$ \\
\hline $\begin{array}{l}\text { NORMAL } \\
\text { EXPONENTIAL } \\
\text { WEIBULL } \\
\text { BETA }\end{array}$ & & & & & \\
\hline
\end{tabular}

Table 5. Most fitting PDF for the frequency data sets.

\begin{tabular}{lcccccc}
\hline DISTRIBUTION $\begin{array}{c}\text { JINJA } \\
\text { IND-IGANG }\end{array}$ & $\begin{array}{c}\text { TORR } \\
\text { MAIN-BUSI }\end{array}$ & $\begin{array}{c}\text { BULG- } \\
\text { PALLIS }\end{array}$ & LIRA-GULU & $\begin{array}{c}\text { LIRA- } \\
\text { MASD/ } \\
\text { APAAC }\end{array}$ & HOIMA-MASINDIBOMBO-WABIGAL & $\begin{array}{c}\text { PIONEER } \\
\text { MALL }\end{array}$ \\
\hline $\begin{array}{l}\text { NORMAL } \\
\text { EXPONENTIAL }\end{array}$ \\
$\begin{array}{l}\text { WEIBULL } \\
\text { BETA }\end{array}$ & & & & & & \\
\hline
\end{tabular}

If the computed value is less than the table value then the data fits the distribution.

\subsubsection{Outage Duration and Frequency PDF Shapes}

The outage duration and frequency data for the various lines considered were sketched using the properties of the best fitting PDF as determined by the chi-square tests. This paper shows shapes for two of the seven studied lines in Figures 1-4. The shapes give an indication that the data has different parameter properties and shapes hence different PDFs.

Jinja Industrial-Iganga $33 \mathrm{kV}$ duration and frequency data follow the Weibull PDF $\alpha=23.199$ and $\beta=1.2163$ and $\alpha=19.175$ and $\beta=1.6046$ respectively.

Tororo-Main-Busia $33 \mathrm{kV}$ duration and frequency data follow the Weibull PDF $\alpha=0.804$ and $\beta=3.405$, Minimum $=0$ and Maximum $=311.4$ and $\alpha=$ 2.739 and $\beta=3.57$, Minimum $=0$ and Maximum $=60$ respectively.

\subsection{Sequential Model for Reliability Computation}

An MS Excel based MCS was used designed and used to compute the reliability indices. It involved the randomization of the data based on the selected fitting PDF as determined by the Chi-square tests. The generated outage scenarios were used to compute the total outage durations per year $(r)$, the rate of outage $(\lambda)$ and the unavailability $(U)$. These were used to compute the indices for each of the three possible evacuation technologies. These include;

1) An overhead tie line and an overhead evacuation line

2) A complete cable run between the generation station and the distribution substation

3) A cable tie line and an overhead evacuation line

For each of these configurations, a digital logic was established based on the annual outage durations and frequencies from the random scenarios and the 


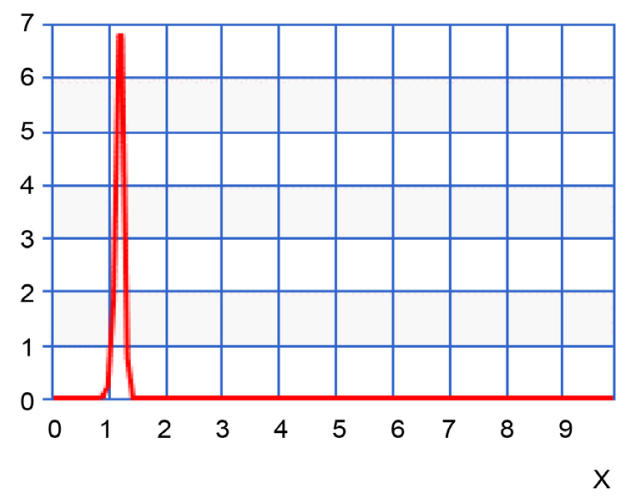

Figure 1. Outage duration data-shape for the Jinja Industrial-Iganga $33 \mathrm{kV}$ line.

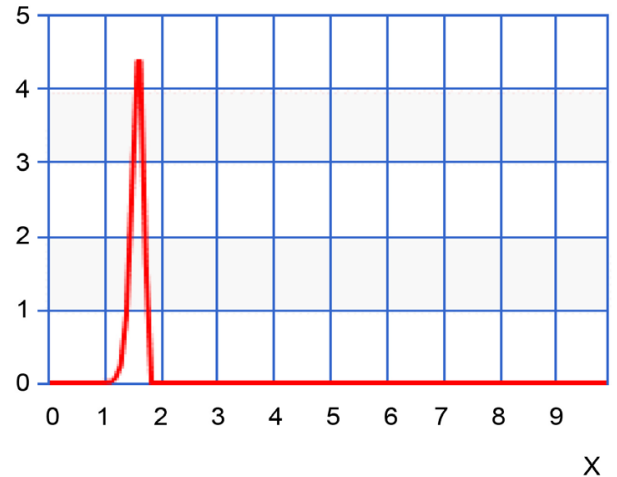

Figure 2. Outage frequency data-shape for the Jinja Industrial-Iganga $33 \mathrm{kV}$ line.

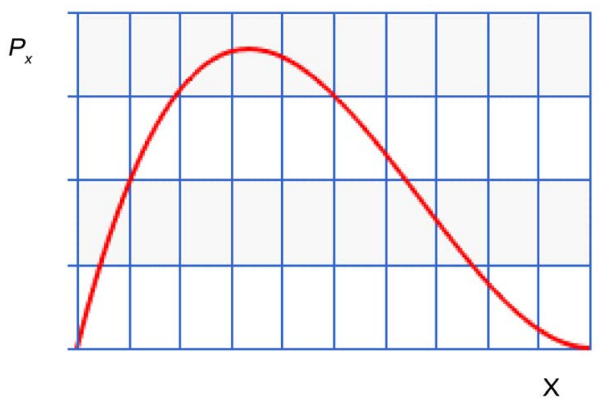

Figure 3. Outage duration data-shape for the Tororo-Main-Busia $33 \mathrm{kV}$ line.

conditions for generation from the solar power station. Uganda has a monthly average 200 solar hours. Considering the 200 solar hours in the areas of study and the Required Plant Availability (RPA) for any power station of 96\% [11], the condition for each configuration were determined. ASAI was computed as the average of the digital outcomes. This was then used to compute ENS, SAIDI, SAIFI and CAIDI.

The flow chart for sequential model used to compute the reliability indices is shown in Figure 5. 


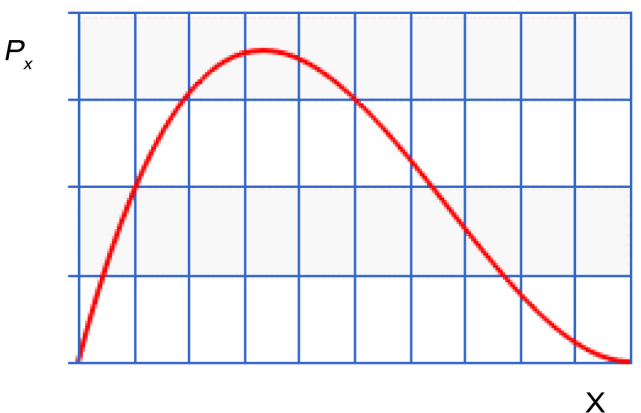

Figure 4. Outage frequency data-shape for the Tororo-Main-Busia $33 \mathrm{kV}$ line.

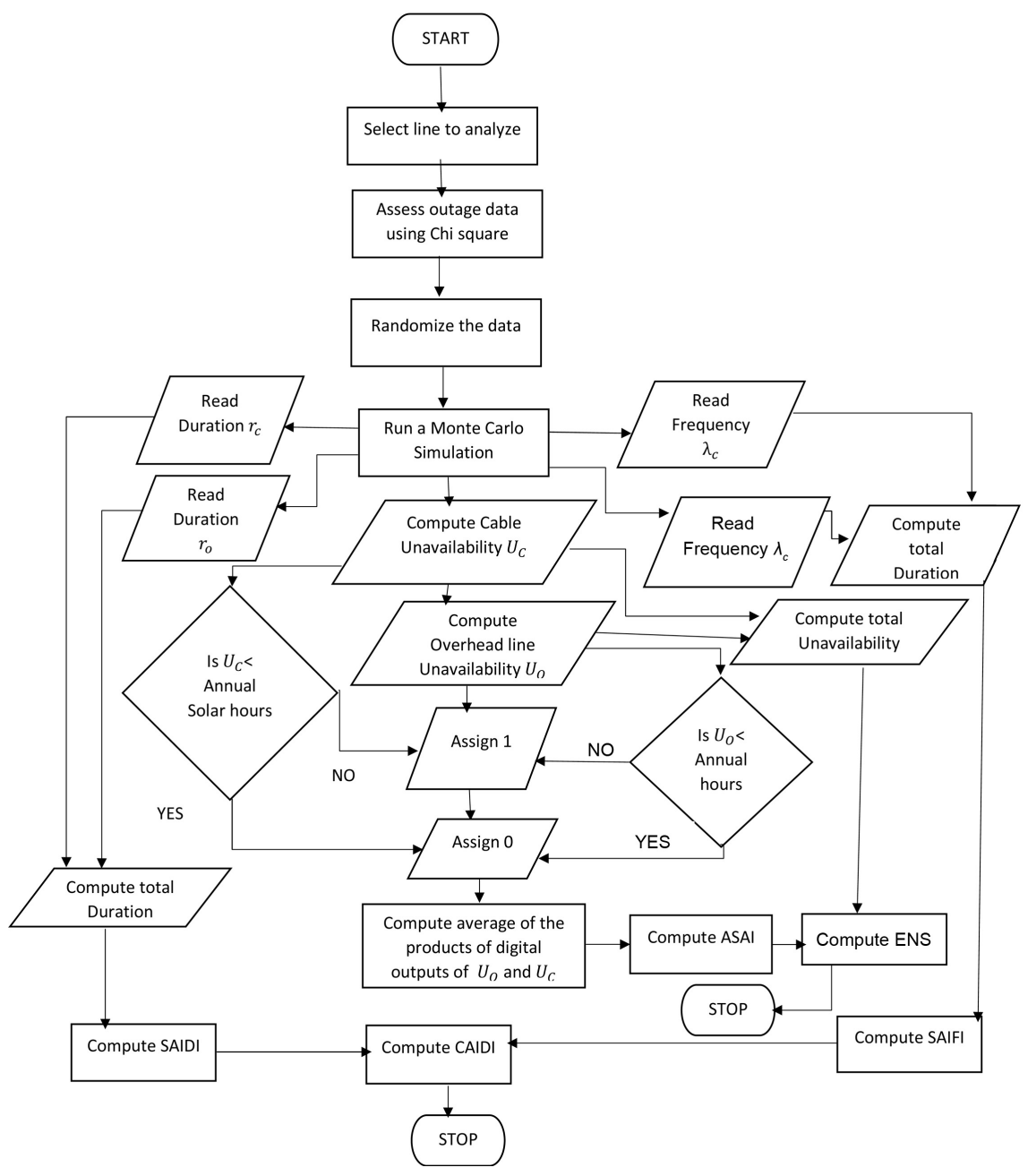

Figure 5. Flow chart for sequential model used in computing reliability indices.

\section{Results and Discussion of the Study}

\subsection{Validation of the Model Using RBTS}

The developed reliability analysis model was tested against the standard RBTS [12] [13]. The inputs applied to the reliability model were the network characteristics (failure and repair rates) of the components of Figure 6 of the RBTS 


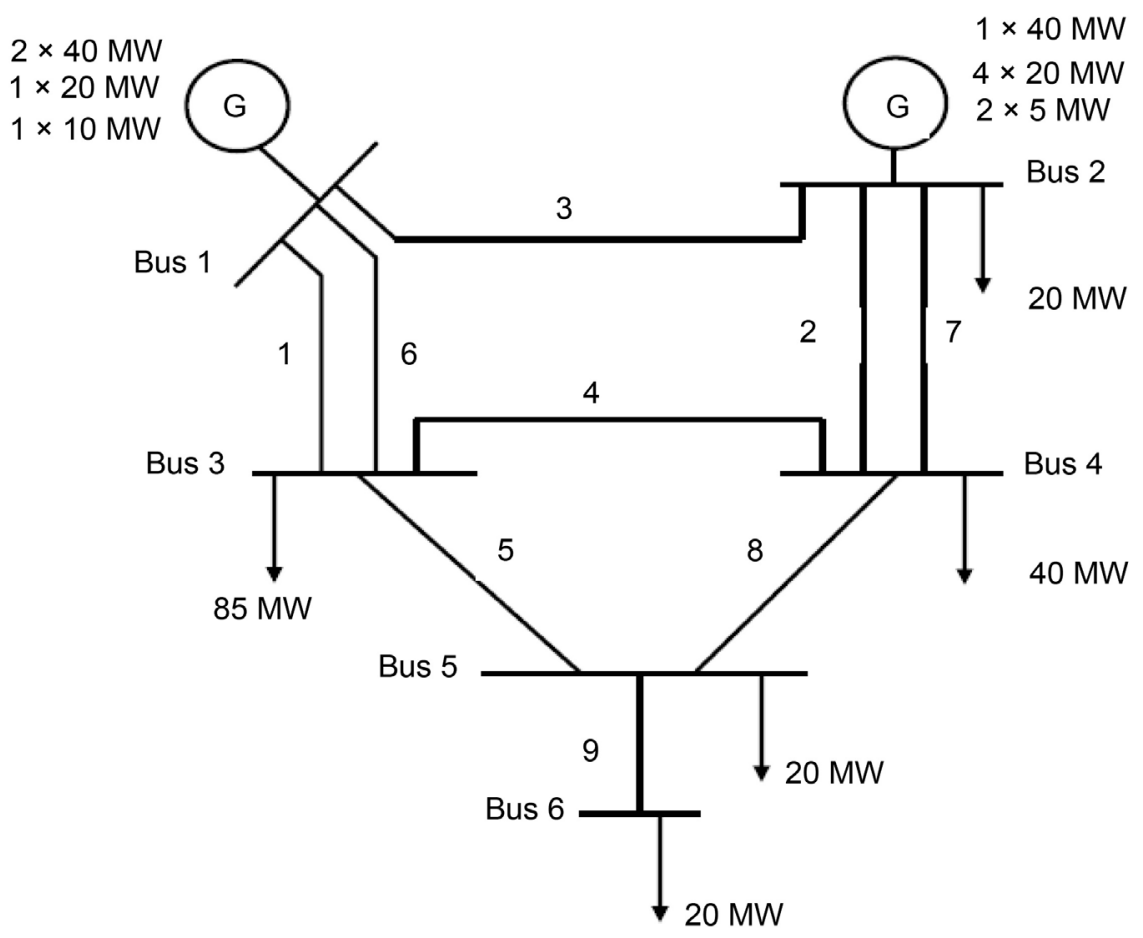

Figure 6. Single line diagram of RBTS [14].

HLIII. The index values computed from the reliability model were then compared with already published index values. Table 6 shows the percentage variation of the results for the model from the standard published RBTS for Bus 5, load points 1, 12 and 23 and the entire bus. The results show that the developed model results do not deviate significantly from the published RBTS results and can therefore be applied to the study.

\subsection{Assessing Variability of the Reliability Indices}

The five computed reliability indices were analyzed to determine whether they are averages (as in the deterministic analysis) or PDFs as in the stochastic analysis. The analysis proved that only the ASAI is an average. SAIFI, SAIDI, CAIDI and ENS are variable and hence follow different PDFs. This was proved by analysis of the resultant indices using the chi square method for goodness of fit. The PDF shapes for some of the reliability indices for two evacuation lines are shown in Figure 7 and Figure 8.

\subsection{SAIDI Results}

The SAIDI results were computed for each of the 7 overhead lines and the underground cable network. The results show that the underground cable configuration has a better SAIDI value as compared to the overhead and combined networks. The SAIDI value for the cable network was 2.99 as the upper limit for the $95 \%$ confidence interval for the proposed configuration evacuation means. The SAIDI values for the other lines are shown in Table 7 for the overhead and 
Table 6. Bus 5 Load point 1 RBTS comparison.

\begin{tabular}{ccccc}
\hline & LP 1 & LP 12 & LP 23 & ENTIRE BUS 5 \\
\hline LOAD LEVEL & 0.4269 & 0.3786 & 0.6247 & 11.29 \\
ASAI & 0.1537 & 0.1438 & 0.1788 & -0.0042 \\
ENS (MWh/yr) & 0.8159 & -3.1319 & 0.7956 & -0.4936 \\
SAIFI (fr/syst.cust) & 1.4053 & -1.1865 & 0.6456 & -0.3087 \\
SAIDI (fr/syst.cust) & 0.6631 & -3.3962 & 0.6179 & -0.3475 \\
CAIDI (hr/cust) & -0.7531 & -2.1839 & -0.028 & -0.0386 \\
\hline
\end{tabular}

Table 7. SAIDI rank results.

\begin{tabular}{ccc}
\hline & Overhead & Combined \\
\hline BULANGIRA-PALLISA & 17.77 & 13.88 \\
HOIMA-MASINDI & 17.91 & 14 \\
BOMBO-WABIGALO & 20.87 & 16.89 \\
JINJA IND-IGANGA & 35.21 & 31.25 \\
LIRA-GULU & 110.52 & 106.65 \\
TORORO MAIN-BUSIA & 132.97 & 129.01 \\
LIRA-MASINDI/APAAC & 371.35 & 367.3 \\
\hline
\end{tabular}

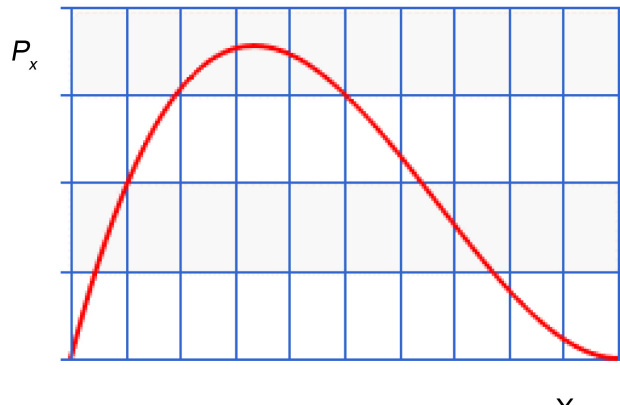

X

Figure 7. SAIDI Beta PDF for the Lira-Gulu 33 $\mathrm{kV}$ overhead configuration.

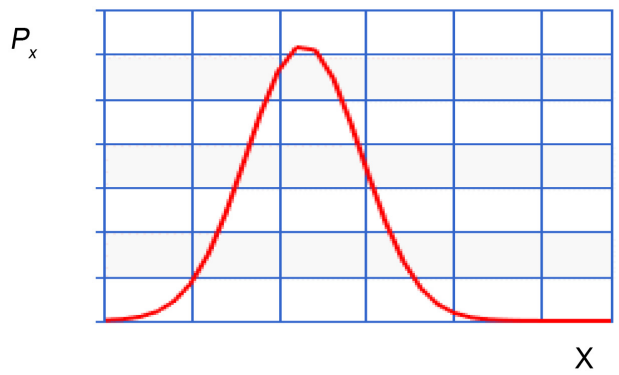

Figure 8. CAIDI Normal PDF for Lira-Gulu 33 $\mathrm{kV}$ overhead configuration.

combined configurations.

Jinja Industrial-Iganga $33 \mathrm{kV}$ line ranks fourth of the 7 selected lines for the 
computed SAIDI results. This implies that if Bulangira-Pallisa $11 \mathrm{kV}$, Hoima-Masindi $33 \mathrm{kV}$ or Bombo-Wabigalo $33 \mathrm{kV}$ lines were considered for both the overhead and the combined configurations, the customers would experience shorter interruptions than Jinja Industrial-Iganga $33 \mathrm{kV}$ line. However, if Lira-Gulu $33 \mathrm{kV}$, Tororo main-Busia $33 \mathrm{kV}$ or Lira-Masindi/Apaac $33 \mathrm{kV}$ lines were considered for the evacuation of the $15 \mathrm{MW}$, the customers would experience longer interruptions than on Jinja Industrial-Iganga $33 \mathrm{kV}$ line. This implies that Pallisa, Masindi and Wabigalo would experience shorter interruptions if selected for location of the DG than Mayuge. However Gulu, Busia and Apaac would experience longer interruptions than Mayuge. The distribution company and the customers will therefore benefit more if a decision is taken to locate the DG plant either Pallisa, Masindi or Wabigalo and not Mayuge.

\subsection{SAIFI Results}

The SAIFI values were computed as well for the lines considered. The SAIFI value for the cable network was 0.236 as the upper limit for the $95 \%$ confidence interval for the proposed configuration evacuation means. This shows that the cable network is preferred to the overhead network. The SAIFI values for the various lines are indicated in Table 8.

Considering the SAIFI results, the Jinja Industrial-Iganga $33 \mathrm{kV}$ line ranks second of the 7 selected lines for the overhead and combined configurations. If Bulangira-Pallisa line was considered for the evacuation of the $15 \mathrm{MW}$, it would imply that customers experience fewer interruptions as compared to selecting Jinja-Industrial $33 \mathrm{kV}$ line. Selecting any other considered line would imply that customers experience more interruptions as compared to Jinja Industrial-Iganga $33 \mathrm{kV}$ line. This implies that selection of Pallisa for the DG plant location would result into customers experiencing fewer interruptions as compared to Mayuge. However selection of Wabigalo, Masindi, Gulu, Busia or Apaac would result in customers experiencing more supply interruptions than Mayuge. The distribution company and the customers will therefore benefit more if a decision is taken to locate the DG plant Pallisa as opposed to Mayuge.

\subsection{CAIDI Results}

The CAIDI values for the considered lines are shown in Table 9. The cable

Table 8. SAIFI rank results.

\begin{tabular}{ccc}
\hline & Overhead & Combined \\
\hline BULANGIRA - PALLISA & 0.691 & 0.4617 \\
JINJA IND - IGANGA & 0.823 & 0.62 \\
BOMBO - WABIGALO & 0.847 & 0.7727 \\
HOIMA - MASINDI & 0.996 & 1.4233 \\
LIRA - GULU & 1.712 & 1.4867 \\
TORORO MAIN - BUSIA & 2.35 & 2.1246 \\
LIRA - MASINDI/APAAC & 3.174 & 2.945 \\
\hline
\end{tabular}


Table 9. CAIDI rank results.

\begin{tabular}{ccc}
\hline & Overhead & Combined \\
\hline HOIMA - MASINDI & 17.961 & 18.123 \\
BOMBO - WABIGALO & 24.654 & 27.239 \\
BULANGIRA - PALLISA & 25.727 & 30.057 \\
JINJA IND - IGANGA & 42.799 & 21.958 \\
TORORO MAIN - BUSIA & 56.579 & 60.724 \\
LIRA - GULU & 64.566 & 71.737 \\
LIRA - MASINDI/APAAC & 117.01 & 124.72 \\
\hline
\end{tabular}

configuration has the lowest CAIDI value of 12.7 compared to the overhead lines for the upper limit for the $95 \%$ confidence interval for the proposed configuration evacuation means.

The CAIDI results rank Jinja Industrial-Iganga $33 \mathrm{kV}$ line as fourth and second for the overhead and combined configuration respectively. Choosing Hoima-Masindi $33 \mathrm{kV}$, Bombo-Wabigalo $33 \mathrm{kV}$ and Bulangira-Pallisa $11 \mathrm{kV}$ for the overhead configuration would result in a lower number of customer interruption durations per affected customer as compared to the Jinja Industrial-Iganga $33 \mathrm{kV}$ evacuation. All other lines would result in a lower number of customer interruption durations per affected customer. For the combined configuration, only Hoima-Masindi $33 \mathrm{kV}$ line would have a lower number of customer interruption durations per affected customer than the Jinja Industrial-Iganga $33 \mathrm{kV}$ line. All other lines in the study will result in a bigger number of customer interruption durations per affected customer. A decision to locate the DG plant in Masindi, Wabigalo or Pallisa using the overhead evacuation technology would result in a less number of customer interruption durations per affected customer as compared to Mayuge and more if located in Gulu or Apaac. However, using the combined line evacuation technology, locating the DG plant in Masindi would result in a smaller number of customer interruption durations per affected customer than in Mayuge. All other considered locations considered for the study would result into a bigger number of customer interruption durations per affected customer. The distribution company and the customers would therefore benefit more if Hoima, Wabigalo or Pallisa were chosen for the location of the DG plant using overhead configuration instead of Mayuge. Using the combined configuration, the distribution company and the customers would benefit more only if the DG plant was located in Masindi and not Mayuge.

\subsection{ASAI Results}

The ASAI values were computed as well. These are shown in Table 10. The cable configuration ASAI was the highest at 0.9962 compared to the overhead networks. Table 10 ranks the ASAI values for the overhead and combined line configuration.

Jinja Industrial-Iganga $33 \mathrm{kV}$ line ranks fourth for the ASAI results. This 
Table 10. ASAI rank results.

\begin{tabular}{ccc}
\hline & Overhead & Combined \\
\hline BULANGIRA - PALLISA & 0.93547 & 0.906 \\
BOMBO - WABIGALO & 0.93935 & 0.8989 \\
HOIMA - MASINDI & 0.9247 & 0.8897 \\
JINJA IND - IGANGA & 0.83605 & 0.8006 \\
LIRA - GULU & 0.5429 & 0.5425 \\
TORORO MAIN - BUSIA & 0.38782 & 0.3734 \\
LIRA-MASINDI/APAAC & 0.0545 & 0.0511 \\
\hline
\end{tabular}

implies that choosing Bulangira-Pallisa $11 \mathrm{kV}$, Bombo-Wabigalo $33 \mathrm{kV}$ line or Hoima-Masindi $33 \mathrm{kV}$ line will result into having more customer hours of available service as demanded than the Jinja Industrial-Iganga $33 \mathrm{kV}$ line. Choosing Lira-Gulu $33 \mathrm{kV}$, Tororo Main-Busia $33 \mathrm{kV}$ and Lira-Masindi/Apaac $33 \mathrm{kV}$ lines will however result less customer hours of available service as compared to demanded hours. This implies that customers would experience more hours of available service as demanded if the DG plant was located in Pallisa, Wabigalo or Masindi than Mayuge. Customers would however experience less hours of available service as demanded if the DG plant was located in Lira, Busia or Apaac. Customer would therefore benefit more if the plant was located in Pallisa, Wabigalo or Masindi and not Mayuge.

\subsection{ENS Results}

The ENS values were computed as well with the consideration of the targeted 15 MW to be evacuated onto the network. The ENS for the cable configuration was the lowest with $1.7731 \mathrm{GWh}$. The ENS values for the other overhead and combined lines are shown in Table 11.

Jinja Industrial-Iganga $33 \mathrm{kV}$ line ranks fifth using the ENS comparison basis. This implies that the deemed energy would be less if Hoima-Masindi $33 \mathrm{kV}, \mathrm{Bu}-$ langira-Pallisa $11 \mathrm{kV}$, Bombo-Wabigalo $33 \mathrm{kV}$ and Lira-Masindi/Apaac were considered for the evacuation of the $15 \mathrm{MW}$ instead of Jinja Industrial-Iganga 33 $\mathrm{kV}$ line. The deemed energy would however be more if Tororo Main-Busia 33 $\mathrm{kV}$ and Lira-Gulu $33 \mathrm{kV}$ lines were considered for the evacuation of the $15 \mathrm{MW}$. This implies that a decision to locate the DG plant in Masindi, Pallisa, Wabigalo or Apaac and not Mayuge would be more beneficial to the regulator and the distribution company as it will yield less deemed energy hence less deemed energy costs to the regulator and more sales to the distribution company. A decision to locate the DG plant in Busia or Gulu will however yield more deemed energy hence incurring more deemed energy costs hence undesirable to the regulator and the distribution company.

\subsection{Selection of the Best Evacuation Line}

Different evacuation lines rank differently for different reliability indices. The 
Table 11. ENS rank results.

\begin{tabular}{ccc}
\hline & Overhead & Combined \\
\hline HOIMA - MASINDI & 9.4302 & 7.663 \\
BULANGIRA - PALLISA & 9.529 & 7.682 \\
BOMBO - WABIGALO & 11.101 & 9.388 \\
LIRA - MASINDI/APAAC & 11.2291 & 11.852 \\
JINJA IND - IGANGA & 16.6832 & 15.463 \\
TORORO MAIN - BUSIA & 27.8846 & 28.155 \\
LIRA - GULU & 36 & 34.267 \\
\hline
\end{tabular}

ranking for each line based on the particular index is shown in Table 12.

Different reliability indices represent different implications to the various stakeholders. Based on the reliability indices studied for the selected lines, a number of decisions can be taken on the location for the DG plant based on the interests of the various stakeholders. ASAI is a measure of the supply availability when needed by the customer. Basing the decision to locate the DG plant on the ASAI rank would therefore benefit the customer. As such the best location would be Pallisa. ENS is important to the regulator who computes deemed energy costs, the investor that seeks to maximize evacuation on to the grid and the distribution company that seeks to maximize sales. Basing the decision to locate the DG plant on ENS ranking would therefore benefit the regulator, the investor and the distribution company. Masindi would be the best location for the DG plant based on ENS ranking that would consider the interests of the regulator, investor and the distribution company. SAIDI, SAIFI and CAIDI are vital indices to both the distribution company and the customer. Based on the SAIDI and SAIFI ranks, Pallisa would be the best location for the DG plant. Based on the CAIDI rank, Masindi would be the best location for the DG plant to for the distribution company and the customers. In order to make a decision that caters for all stakeholder interests the average rank for all the indices was computed. This ought to be the guideline to the investor when deciding on the best evacuation technology and location.

\subsection{Selection of the Best Evacuation Technology}

The three (3) evacuation technologies addressed in the study were assessed for each of the lines. The results are shown in the graph in Figures 9-13. The cable network is most suited for evacuation considering all stakeholders as it has the lowest SAIDI, SAIFI, CAIDI and ENS and the highest ASAI. The overhead configuration is better suited than the combined configuration for the interests of the distribution company that considers SAIDI and SAIFI. The CAIDI graphs indicate that the combined configuration network would be better suited than the overhead with the exception of Jinja Industrial-Iganga line whose overhead configuration network is better suited than the overhead network. The ASAI graphs indicate that the overhead network configuration is better suited than the 
Table 12. Line comparison based on reliability indices.

\begin{tabular}{ccccccc}
\hline & ASAI & ENS & SAIDI & SAIFI & CAIDI & $\begin{array}{c}\text { Average } \\
\text { Ranking }\end{array}$ \\
\hline BULANGIRA - PALLISA & 1 & 2 & 1 & 1 & 3 & 1.6 \\
HOIMA - MASINDI & 3 & 1 & 2 & 4 & 1 & 2.2 \\
BOMBO - WABIGALO & 2 & 3 & 3 & 3 & 2 & 2.6 \\
JINJA IND - IGANGA & 4 & 5 & 4 & 2 & 4 & 3.8 \\
LIRA - GULU & 5 & 7 & 5 & 5 & 6 & 5.6 \\
TORORO MAIN - BUSIA & 6 & 6 & 6 & 6 & 5 & 5.8 \\
LIRA-MASINDI/APAAC & 7 & 4 & 7 & 7 & 7 & 6.4 \\
\hline
\end{tabular}

Configuration comparison for SAIDI

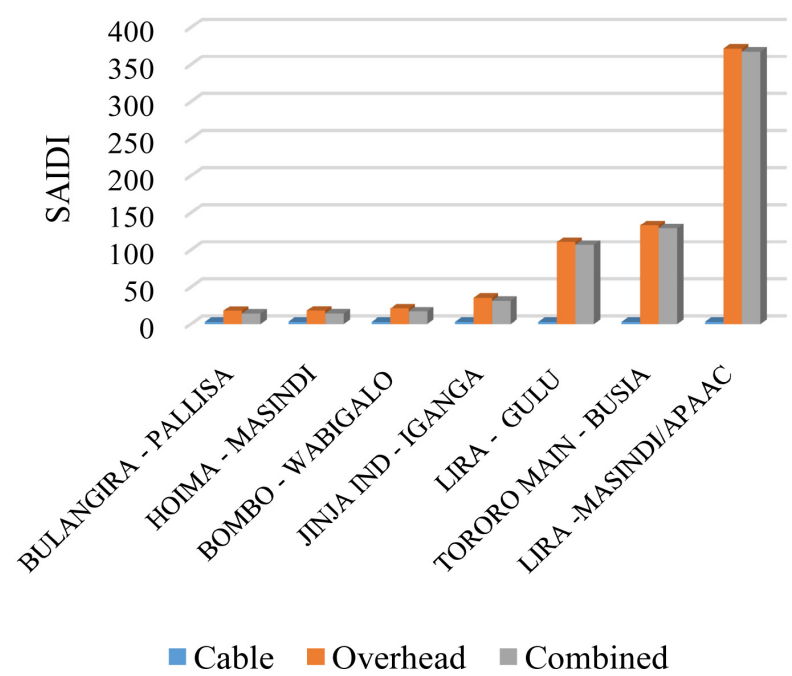

Figure 9. Network configuration comparison for SAIDI.

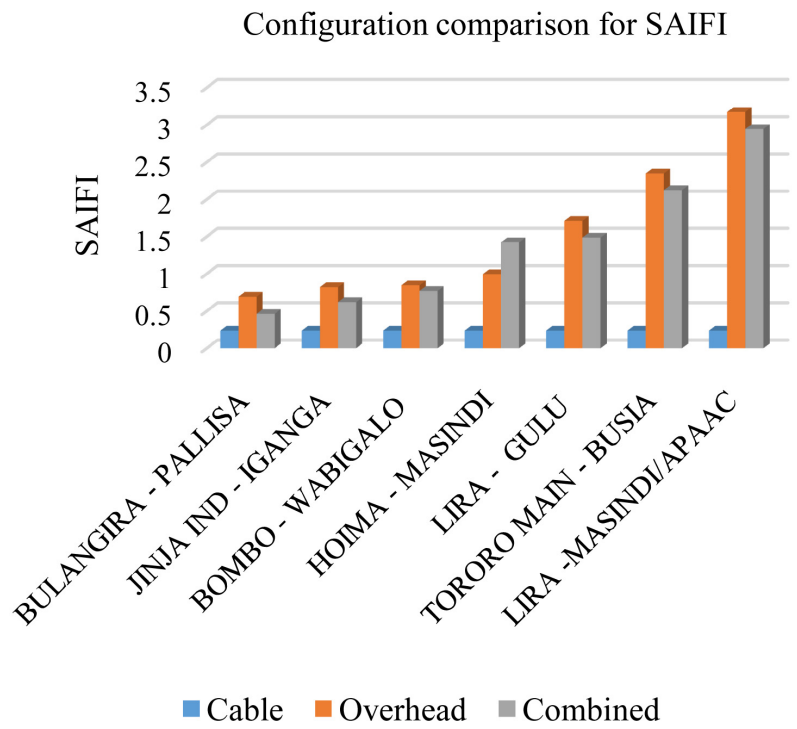

Figure 10. Network configuration comparison for SAIFI. 


\section{Configuration comparison for CAIDI}

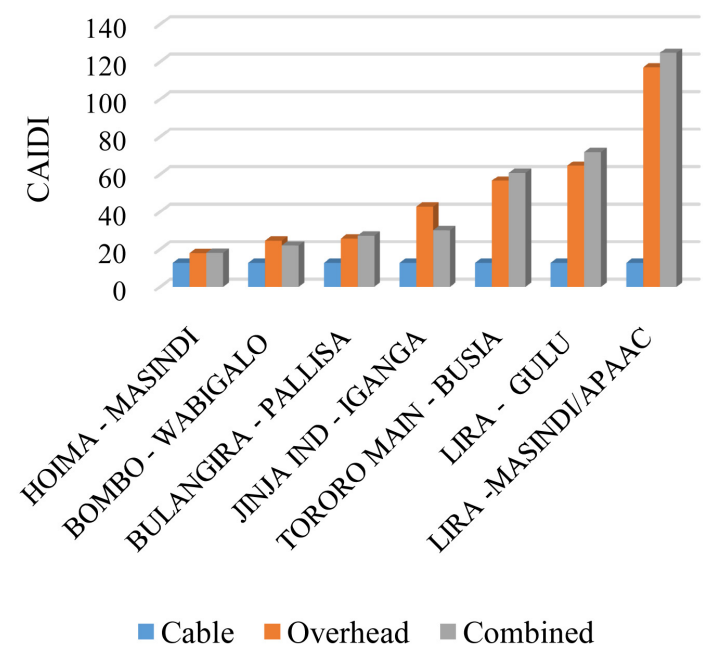

Figure 11. Network configuration comparison for CAIDI.

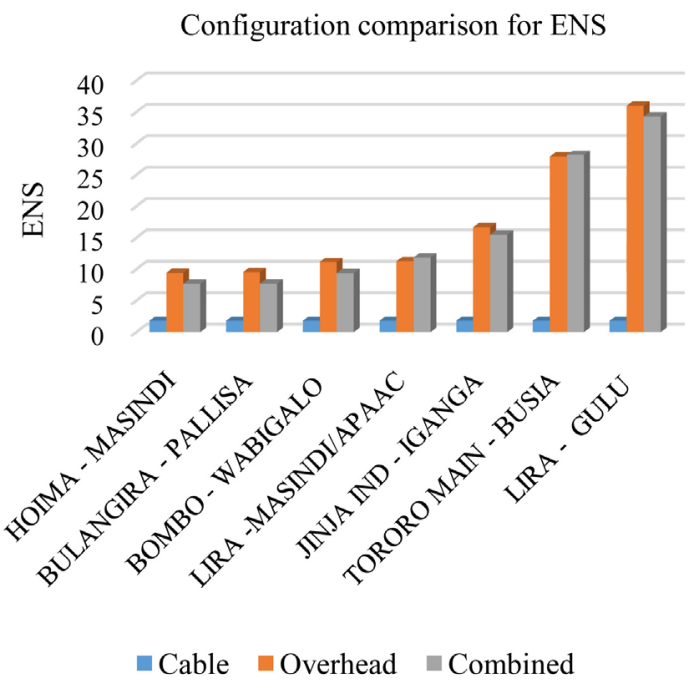

Figure 12. Network configuration comparison for ENS.

combined network. This would be considered for the interests of the customers. There is less deemed energy (ENS) on evacuating using the combined network configuration than the overhead configuration. This implies that it would be more desirable to the distribution company and the regulator who have interest in deemed energy computation to use the combined network configuration for the evacuation from the DG plant.

\subsection{The Impact of Reliability on the Evacuation}

Reliability has a major impact on the evacuation. The impact of reliability on the maximum possible evacuation of the $15 \mathrm{MW}$ from the solar power station can be assessed by analyzing its impact on the expected ENS and the anticipated project 
Configuration comparison for ASAI
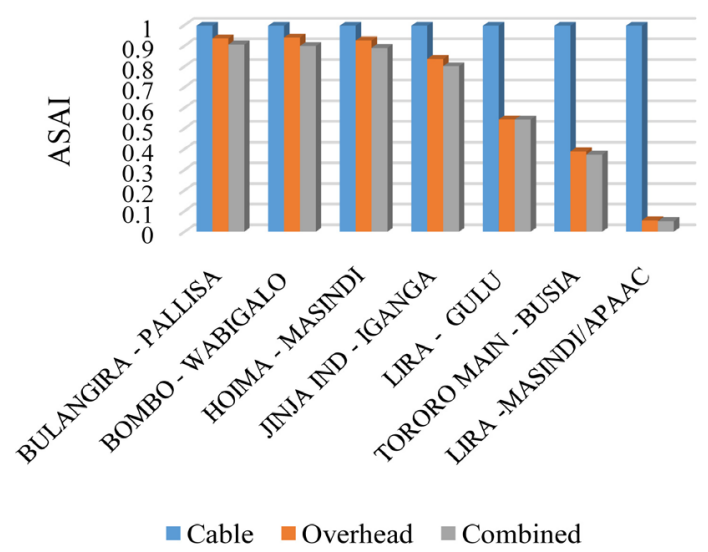

Figure 13. Network configuration comparison for ASAI.

payback period.

\subsubsection{Expected ENS Costs}

This was done by assessing the cost of the ENS for the different lines considering the evacuation technologies. The ENS cost was computed using Equation (3). The unit cost for the Mayuge solar plant was stated as USD 0.11 per kWh.

$$
\text { Deemed energy cost }=\text { ENS cost }=\text { ENS } \times \text { unit cost }
$$

The cable network was found to have the lowest ENS cost of $0.1948 \mathrm{~m}$ USD in the $95 \%$ confidence interval. The expected ENS costs for the lines are shown in Table 13 for both configurations. The results indicate that more money will be lost in deemed energy on considering Busia or Gulu instead of Mayuge for the location of the DG plant. Less costs will however be incurred on deemed energy if Masindi, Pallisa, Wabigalo or Apaac were considered instead of Mayuge.

\subsubsection{Project Payback Period}

A project payback period is the time taken for the investor to recoup the money invested in a particular project. Currently, the project payback period is calculated using Equation (4).

$$
\text { Payback period }=\frac{\text { Project cost }}{\text { Maximum possible evacuation } \times \text { Unit cost }}
$$

The proposed solar power project is a 30 million USD project under the investor, Emerging Power Uganda. The investor expects to sell power to UETCL at USD0.11 per kWhr, a price that will guarantee ROI. Using Equation (4), the project payback period was computed as 7.58 years. This however does not consider deemed energy (ENS) costs when estimating the project payback period. The research therefore proposed Equation 5 to compute the payback period that incorporates deemed energy (ENS).

$$
\text { Payback period }=\frac{\text { Project cost }}{(\text { Maximum possible evacuation }- \text { ENS }) \times \text { Unit cost }}
$$


Table 13. ENS costs.

\begin{tabular}{ccc}
\hline & Overhead & Combined \\
\hline HOIMA - MASINDI & 1.037 & 0.843 \\
BULANGIRA - PALLISA & 1.048 & 0.845 \\
BOMBO - WABIGALO & 1.221 & 1.033 \\
LIRA - MASINDI/APAAC & 1.235 & 1.304 \\
JINJA IND - IGANGA & 1.835 & 1.701 \\
TORORO MAIN - BUSIA & 3.067 & 3.097 \\
LIRA - GULU & 3.96 & 3.769 \\
\hline
\end{tabular}

The decision to evacuate the generated power using the different lines was analyzed. Table 14 shows the projected payback periods on evacuating using the different lines using different evacuation technologies. It is clear that the computed anticipated payback period considering deemed energy is longer than that which does not consider ENS as calculated using Equation (8). The project payback period on evacuating using the underground cable network is 8.4 years. This is a shorter anticipated period as compared to the periods on using the combined and overhead networks. The investor will recover the invested amounts in a much shorter time if the DG plant is located in Masindi or Pallisa or Wabigalo or Apaac than Mayuge. It will however take a much longer time if a decision is taken to locate the DG plant in Busia or Gulu as compared Mayuge.

\subsection{Determination of Threshold ENS for Evacuation Consideration}

This paper proposes a threshold ENS to be set for any the investor to consider when deciding to locate the DG plant. This shall be set in the PPA by the regulator as the ENS value for the selected evacuation line above which the investor shall be penalized. It is the inherent ENS value for the evacuation network as indicated in Table 11. The investor therefore decides on the location well informed about the repercussion of the network's annual ENS performance. It would therefore be necessary to invest in network reliability improvement for any particular evacuation line in consideration. This can be achieved through installation of various components that minimize outage durations and frequencies on distribution networks.

\section{Conclusions}

This paper analyzed the decision by Emerging Power Uganda to locate the investment in the $15 \mathrm{MW}$ solar power station in a particular location using a given evacuation line. Based on the results presented for all the reliability indices, it is clear that the selected Jinja Industrial-Iganga $33 \mathrm{kV}$ line was not the best option for this evacuation. Additionally, a model is proposed that can be used as a network reliability analysis tool for distribution companies, distributed generation 
Table 14. Project payback periods.

\begin{tabular}{ccc}
\hline \multicolumn{2}{c}{ Payback period (years) } & \\
\hline & Overhead & Combined \\
\hline HOIMA - MASINDI & 10.4 & 9.8 \\
BULANGIRA - PALLISA & 10.5 & 9.8 \\
BOMBO - WABIGALO & 11.1 & 10.4 \\
LIRA - MASINDI/APAAC & 11.1 & 11.4 \\
JINJA IND - IGANGA & 14.1 & 13.8 \\
TORORO MAIN - BUSIA & 33.7 & 43.3 \\
LIRA - GULU & Never & Never \\
\hline
\end{tabular}

companies and the electricity regulator. This can be a guideline to investment decisions in DG considering the various stakeholders.

It is necessary for each stakeholder to design requirements and considerations that will guide the decision to invest and locate a DG station in a particular area.

Investor requirements: the investors are the main stakeholder as they make the decision to invest millions of dollars in a particular project with the aim of selling energy to the system operator to realize ROI. The sales will however not be as forecast if the network cannot deliver the generated energy on to the distribution grid. It is therefore necessary that the investor considers the following recommendations:

1) Decide on the location of the DG plant based on the individual index ranking or the average ranking in consideration of the various stakeholders as shown in Table 12. The average ranking will ensure incorporation of the interests of all stakeholders.

2) The investor is interested in maximizing sales to ensure quick Returns on Investment (ROI). As such, it is necessary to compute the anticipated payback periods as a prioritization criterion. This will ensure that investment is located where sales will yield a quicker payback based on the reliability of the evacuation line.

3) Consider underground cable evacuation technology. This paper indicates that an underground network has better indices than any other.

Electricity regulator requirements: the electricity regulator oversees the agreement between the system operator and the generation company. The regulator also protects the interests of the nationals as investment directly impacts the price of electricity in the country. It is therefore in the regulator's best interest to ensure that the nationals pay for an investment that has served its intended purpose and benefit to them. As such the regulator ought to ensure the following when signing the PPA:

1) The deemed energy clause makes consideration for the implication to the generator for failure to deliver energy due to reliability challenges that should have been considered and mitigated at the point of selection of an evacuation line for the DG plant. The investor should be tasked with ensuring that the in- 
herent ENS is not exceeded hence should be considered as the threshold.

Electricity distributor requirements: the electricity distributor has keen interest supplying quality and reliable supply to the customers. Network reliability studies therefore enable the distributor to utilize the more reliable distribution infrastructure to evacuate power on to the grid. Different indices have different implications to the customers.

1) Industrial customers with sensitive machine start up mechanisms are affected more by frequent power curtailments. This implies that SAIFI rank results would be the best to consider when choosing the location for the DG plant.

Small businesses are more affected by long outage periods. This implies that SAIDI and CAIDI rank results would be the best to consider in making a decision on the line that intends to serve such customers.

\section{Acknowledgements}

This work was financially supported by the Africa Center of Excellence in Materials, Product Development and Nanotechnology (MAPRONANO ACE) at the College of Engineering, Design, Art \& Technology (CEDAT), Makerere University.

\section{Conflicts of Interest}

The authors declare no conflicts of interest regarding the publication of this paper.

\section{References}

[1] Jenkins, N., Ekanayake, J. and Strbac, G. (2010) Distributed Generation. The Institution of Engineering and Technology, London. https://doi.org/10.1049/PBRN001E

[2] Ministry of Energy and Mineral Development (2018) The Electricity Act 1999. Retrieved from Energy and Minerals.

http://npa.ug/wp-content/uploads/2018/01/Energy-Sector-Development-plan-Final. pdf

[3] Ministry of Energy and Mineral Development (2015) Uganda's Sustainable Energy for ALL (SE4ALL) Initiative Action Agenda. http://www.energyandminerals.go.ug/ https://www.seforall.org/sites/default/files/Uganda_AA_EN_Released.pdf

[4] Ministry of Finance, Planning and Economic Development (2016) Uganda Vision 2040. Kampala.

https://www.jlos.go.ug/index.php/document-centre/government-of-uganda-plannin g-strategies/274-uganda-vision-2040/file+\&cd=1\&hl=en \&ct=clnk\&gl=ug:UPPC

[5] Electricty Regulatory Authority (2015) GET FiT Uganda: Annual Report 2015. https://www.era.or.ug/index.php/resource-centre/publications/annual-reports

[6] Pabla, A. (2011) Electric Power Distribution: Sixth Edition. McGraw-Hill Professional, New York.

[7] Wang, H., Zhu, N. and Bai, X. (2015) Reliability Model Assessment of Grid-Connected Solar Photovoltaic System Based on Monte-Carlo. Applied Solar Energy, 51, 262-266. https://doi.org/10.3103/S0003701X15040192

[8] Yun, S.-Y., Kim, J.-C., Moon, J.-F., Park, C.-H., Park, S.-M. and Lee, M.-S. (2003) 
Reliability Evaluation of Radial Distribution System Considering Momentary Interruptions. 2003 IEEE Power Engineering Society General Meeting. Toronto, 13-17 July 2003, 548-555.

[9] Africa-EU Renewable Energy Cooperation Programme (RECP) (2018) Renewable Energy Potential-Uganda.

https://www.africa-eu-renewables.org/market-information/uganda/renewable-ener gy-potential/

[10] Brown, R., Engel, M. and Spare, J. (2005) Making Sense of Worst-Performing Feeders. IEEE Transactions on Power Systems, 20, 1173-1178. https://doi.org/10.1109/TPWRS.2005.846069

[11] The Republic of Uganda (2013) Power Purchase Agreement Relating to the Power Purchase at a Comlex between UETCL and GENCO.

http://www.uetcl.com/Get_Fit_PPA\%20_final_SG_approved_version.pdf

[12] Billinton, R. and Jonnavithula, S. (1996) A Test System for Teaching Overall Power Systems Reliability Assessment. IEEE Transactions on Power Systems, 11, 1670-1676. https://doi.org/10.1109/59.544626

[13] Probabilistic Methods Subcommittee (1979) IEEE Reliability Test System. IEEE Transactions on Power Apparatus and Systems PAS-98, 6, 2047-2054. https://doi.org/10.1109/TPAS.1979.319398

[14] Afshar, K. and Barati, M. (2013) A New Approach for Determination and Cost Allocation of Reserve in the Restructured Power System. Electric Power Systems Research, 100, 25-33. https://doi.org/10.1016/j.epsr.2013.02.008 